\title{
Interaction between Glucose and Free Fatty Acid Metabolism in Human Skeletal Muscle
}

\author{
David E. Kelley, ${ }^{* 5}$ Marian Mokan, * Jean-Aime Simoneau," and Lawrence J. Mandarino* \\ Departments of * Medicine, ${ }^{\ddagger}$ Ophthalmology, and The Eye \& Ear Institute, The University of Pittsburgh, Pittsburgh, Pennsylvania 15213; \\ ${ }^{\S}$ Department of Veterans Affairs, Pittsburgh, Pennsylvania 15260; and"Physical Activity Sciences Laboratory, Laval University, Ste-Foy, \\ Quebec GIK 7P4, Canada
}

\begin{abstract}
The mechanism by which FFA metabolism inhibits intracellular insulin-mediated muscle glucose metabolism in normal humans is unknown. We used the leg balance technique with muscle biopsies to determine how experimental maintenance of FFA during hyperinsulinemia alters muscle glucose uptake, oxidation, glycolysis, storage, pyruvate dehydrogenase (PDH), or glycogen synthase (GS). 10 healthy volunteers had two euglycemic insulin clamp experiments. On one occasion, FFA were maintained by lipid emulsion infusion; on the other, FFA were allowed to fall. Leg FFA uptake was monitored with $\left[9,10-{ }^{3} \mathrm{H}\right]-$ palmitate.

Maintenance of FFA during hyperinsulinemia decreased muscle glucose uptake $(1.57 \pm 0.31$ vs $2.44 \pm 0.39 \mu \mathrm{mol} / \mathrm{min}$ per $100 \mathrm{ml}$ tissue, $P<0.01)$, leg respiratory quotient $(0.86 \pm 0.02$ vs $0.93 \pm 0.02, P<0.05)$, contribution of glucose to leg oxygen consumption $(53 \pm 6$ vs $76 \pm 8 \%, P<0.05)$, and PDH activity $(0.328 \pm 0.053$ vs $0.662 \pm 0.176 \mathrm{nmol} / \mathrm{min}$ per $\mathrm{mg}, P<0.05)$. Leg lactate balance was increased. The greatest effect of FFA replacement was reduced muscle glucose storage $(0.36 \pm 0.20$ vs $1.24 \pm 0.25 \mu \mathrm{mol} / \mathrm{min}$ per $100 \mathrm{ml}, P<0.01$ ), accompanied by decreased GS fractional velocity $(0.129 \pm 0.26$ vs $0.169 \pm 0.033$, $P<0.01)$. These results confirm in human skeletal muscle the existence of competition between glucose and FFA as oxidative fuels, mediated by suppression of PDH. Maintenance of FFA levels during hyperinsulinemia most strikingly inhibited leg muscle glucose storage, accompanied by decreased GS activity. (J. Clin. Invest. 1993.92:91-98.) Key words: glucose oxidation • glycogen $\bullet$ free fatty acids $\bullet$ pyruvate dehydrogenase $\bullet$ glycogen synthase
\end{abstract}

\section{Introduction}

$30 \mathrm{yr}$ ago, Randle and his colleagues proposed the existence of a competition between glucose and fatty acids as oxidative fuel sources in muscle, based on studies using rat heart and diaphragm $(1,2)$. Over the ensuing years, as knowledge has been gained concerning the biochemical regulation of fuel homeostasis in muscle, the postulated mechanisms responsible for this

Address correspondence and reprint requests to Lawrence J. Mandarino, Ph.D., Department of Medicine, The University of Texas Health Science Center at San Antonio, 7703 Floyd Curl Drive, San Antonio, TX 78284-7886. Dr. Mokan's current address is The Department of Medicine, Komensky University, Martin, Czechoslovakia.

Received for publication 14 May 1992 and in revised form 30 October 1992.

The Journal of Clinical Investigation, Inc.

Volume 92, July 1993, 91-98 competition have evolved. In its current form, this hypothesis states that elevated FFA oxidation produces an increased acetylCoA/CoA-SH ratio and citrate concentration. The increase in acetyl-CoA activates pyruvate dehydrogenase kinase, which in turn phosphorylates and covalently inhibits pyruvate dehydrogenase (PDH), ${ }^{1}$ the entry point for glucose (as pyruvate) into oxidative metabolism. The increase in citrate would inhibit phosphofructokinase, thus inhibiting glycolysis, leading to an increase in glucose 6-phosphate concentration, which, in turn, would inhibit hexokinase and presumably result in decreased glucose uptake (for reviews, see references 3 and 4 ).

Randle originally proposed that the glucose/fatty acid fuel competition cycle might be responsible for insulin resistance in diabetes (1). Specifically, this fuel competition is thought to explain, at least partially, the decreased rates of glucose disposal and oxidation often observed in non-insulin-dependent diabetes mellitus (NIDDM) and, these decreases in glucose metabolism are associated with increased plasma FFA concentrations and fat oxidation rates postabsorptively and postprandially (5). Recently, Vaag et al. (6) have shown that acipimox, an antilipolytic agent, reduced plasma FFA and fat oxidation, and increased glucose disposal and oxidation in patients with NIDDM, lending support to this hypothesis. On the other hand, Bevilacqua and co-workers found no evidence that increased fat oxidation was responsible for decreased glucose disposal in patients with mild NIDDM (7).

Many investigators have attempted to demonstrate the existence of glucose/ fatty acid fuel competition in humans (815). Although details of the study designs have varied, most have used lipid or heparin infusions to maintain plasma FFA concentrations during an insulin infusion, which otherwise suppresses lipolysis, while systemic glucose disposal and oxidation are measured using isotopic techniques along with systemic indirect calorimetry. Most studies have shown that experimental maintenance of plasma FFA suppresses the ability of insulin to stimulate systemic glucose oxidation and uptake. However, none of those studies assessed the effects of experimental FFA maintenance during an insulin infusion on muscle $\mathrm{PDH}$ activity, the key element in Randle's hypothesis.

Moreover, systemic measurements of glucose metabolism are a composite of glucose metabolism in many tissues, and may not necessarily reflect muscle glucose metabolism. This is especially true for glucose oxidation, where at low physiologic insulin concentrations $(<200 \mathrm{pM})$, muscle glucose oxidation is not the major contributor to systemic glucose oxidation. In addition, the studies using systemic techniques have not as-

1. Abbreviations used in this paper: GS, glycogen synthase; NIDDM, non-insulin-dependent diabetes mellitus; PDH, pyruvate dehydrogenase. 
sessed the impact of FFA on glycolysis, and inhibition of muscle glycolysis is another prediction of the glucose/fatty acid cycle.

The leg arteriovenous balance technique offers an attractive alternative to systemic measurements for more directly assessing how FFA oxidation alters skeletal muscle glucose metabolism in man. Using this technique, it is possible to obtain close estimates of leg muscle glucose uptake, glucose oxidation, and glycolysis; leg muscle glucose storage (glycogen formation) can then be calculated as the difference between glucose uptake, glucose oxidation, and glycolysis (16). Percutaneous biopsy of the vastus lateralis muscle allows the determination of PDH and glycogen synthase (GS) activity directly in a muscle bed that contributes to the measurements of glucose oxidation and storage. We used these techniques in conjunction with a euglycemic clamp in 10 lean, healthy volunteers to determine $(a)$ how plasma FFA concentrations alters leg muscle glucose uptake, oxidation, storage, and glycolysis; and $(b)$ whether decreases in glucose oxidation or storage are accompanied by changes in muscle PDH or GS activities.

\section{Methods}

\section{Subjects}

Informed written consent to participate in these studies was obtained from 10 healthy male subjects. These studies were approved by the University of Pittsburgh Institutional Review Board. The subjects were aged $30 \pm 2 \mathrm{yr}$, with body mass index of $24 \pm 0.7 \mathrm{~kg} / \mathrm{m}^{2}$. Volunteers were in good general health and did not have a family history of diabetes mellitus. To prepare for each study, subjects were instructed to ingest $\geq 200 \mathrm{~g}$ carbohydrate daily for $3 \mathrm{~d}$ preceding each admission and were carefully instructed to avoid exercise on the day before each study. None of the volunteers engaged in competitive or high intensity exercise programs.

\section{Protocol}

Each subject was admitted to the University of Pittsburgh General Clinical Research Center on the evening before being studied on two separate occasions, 1-4 wk apart. Volunteers were fed a $10-\mathrm{kcal} / \mathrm{kg}$ evening meal ( $50 \%$ carbohydrate, $35 \%$ protein, and $15 \%$ fat), and then placed at bedrest and fasted for $12 \mathrm{~h}$. In the morning, catheters were placed in both antecubital veins for infusion of glucose insulin and 9,10- ${ }^{3} \mathrm{H}$-palmitate (New England Nuclear, Boston, MA) in one arm and for infusion of saline or $10 \%$ fat emulsion (Intralipid; Kabi Pharmacia, Clayton, NC) in the other. To perform leg balance studies, a radial artery (20 gauge; Jelco, Tampa, FL) and a femoral vein (16 gauge; Arrow International Inc., Reading, PA), were catheterized for intermittent blood sampling, as previously described (16), and the subjects were allowed to rest for $30 \mathrm{~min}$ before blood sampling. Fractional extraction of FFA across the leg was measured using an infusion of $9,10-{ }^{3} \mathrm{H}$-palmitate $(0.5 \mu \mathrm{Ci} / \mathrm{min})$ that was started at time $t=-120$ min. At time $t=-30 \mathrm{~min}$, to assess basal leg glucose and lipid metabolism, three sets of arterial and femoral venous blood samples were obtained simultaneously at 15 -min intervals over a 30 -min period for determinations of blood glucose, lactate and alanine, plasma FFA, and palmitate specific activity, and arterial plasma insulin. Leg glucose and lipid oxidation rates were estimated by leg indirect calorimetry using arterial and femoral venous blood samples for measurement of $\mathrm{O}_{2}$ and $\mathrm{CO}_{2}$. These samples were obtained simultaneously at 5-min intervals for $30 \mathrm{~min}$. Leg blood flow was determined using mercury strain gauge plethysmography (Hokanson, Bellevue, WA). On completion of basal sampling at time $t=0 \mathrm{~min}$, infusion of insulin was begun at a rate of 15 $\mathrm{mU} / \mathrm{m}^{2}$ per min, (U-100 Humulin R; Eli Lilly and Co., Indianapolis, IN). Arterial blood glucose was measured every $5 \mathrm{~min}$, and euglycemia was maintained with a variable infusion of $50 \%$ dextrose. Infusion of tritiated palmitate was continued throughout. On one occasion, an infusion of $10 \%$ fat emulsion at $1.25 \mathrm{ml} / \mathrm{min}$ was begun simultaneously with the insulin infusion and was continued for $4 \mathrm{~h}$. On the other occasion, saline instead of fat emulsion was infused. The order of the two studies was determined randomly. Leg balance of glucose and arterial plasma insulin and FFA were determined hourly at times $t$ $=60,120$, and 180. At time $t=210$, intermittent blood sampling was repeated for a $30-\mathrm{min}$ period as described above for the basal period, and leg blood flow was measured again. Upon completion of blood sampling at time $t=240$, a percutaneous needle biopsy of the vastus lateralis muscle was performed after superficial injection of $1 \%$ xylocaine, as previously described (17). Muscle samples were frozen in liquid nitrogen within $20 \mathrm{~s}$ and stored in liquid nitrogen until assays of PDH and GS activity were performed. After the muscle biopsy, all infusions were discontinued.

\section{Analyses}

Blood glucose was measured with a glucose analyzer, (Yellow Springs Instruments Corp., Yellow Springs, $\mathrm{OH}$ ). Samples for blood lactate and alanine were deproteinized at bedside with ice-cold 7\% perchloric acid in preweighed tubes. After determining the weight of the blood sample, the supernatant was stored at $-80^{\circ} \mathrm{C}$ for assay $(18,19)$. Arterial and femoral venous blood gas samples were analyzed at the bedside as previously described (16). Briefly, plasma $\mathrm{CO}_{2}$ content was calculated from measured $\mathrm{CO}_{2}$ tension and $\mathrm{pH}$ (System $1304 \mathrm{pH} /$ blood gas analyzer; Allied Instrumentation Laboratory, Lexington, MA), and adjusted to whole blood $\mathrm{CO}_{2}$ content using an empirically derived regression equation (20). Blood oxygen content was determined using a cooximeter (IL282 Co-Oximeter System; Allied Instrument Laboratory, Lexington, MA). Arterial plasma insulin concentrations were determined by radioimmunoassay (21). Plasma FFA concentrations were determined by an enzymatic method (NEFAC kit; Wako Chemicals, Inc., Dallas, TX). Plasma palmitate specific activity was determined with isocratic HPLC separation, using a reverse-phase column (C-18; III Supplies Co., Meriden, CT) with $82 \%$ acetylnitrile/18\% water as the mobile phase and D31-palmitate as an internal standard (22). Plasma palmitate concentrations were determined by comparing the area under each palmitate peak with a standard curve generated using HPLC. Peaks corresponding to palmitate were collected, dried under vacuum, redissolved in a scintillation fluid, and counts in ${ }^{3} \mathbf{H}$ were determined.

\section{Enzyme activity assays}

PDH and GS were assayed in crude mitochondrial and cytosolic fractions of muscle biopsy homogenates as described (17). The PDH assay was performed by monitoring the production of ${ }^{14} \mathrm{CO}_{2}$ from $1-\left[{ }^{14} \mathrm{C}\right]-$ pyruvic acid in a closed system, with collection of ${ }^{14} \mathrm{CO}_{2}$ on filter paper impregnated with methylbenzethonium hydroxide. PDH was assayed $(a)$ in the presence of fluoride ( to inhibit phosphatase activity) and low $\mathrm{Mg}^{2+}$ and $\mathrm{Ca}^{2+}$ as a measurement of $\mathrm{PDH}_{\mathrm{a}}$, which reflects PDH activity in vivo; and $(b)$ in the absence of fluoride and presence of high $\mathbf{M g}^{2+}$ as a measurement of $\mathrm{PDH}_{\mathrm{t}}$, which reflects total $\mathrm{PDH}$ activity. $\mathrm{PDH}_{\mathrm{Fv}}$ was calculated as the ratio $\mathrm{PDH}_{\mathrm{a}} / \mathrm{PDH}_{\mathrm{i}}$. The pyruvate concentration was $1 \mathrm{mM}$. GS activity was determined by monitoring the conversion of UDP-U- $\left[{ }^{14} \mathrm{C}\right]$ glucose into $\left[{ }^{14} \mathrm{C}\right]$ glycogen, with collection and ethanol precipitation of glycogen on filter paper squares. GS was assayed in the presence of fluoride and $0.1\left(\mathrm{GS}_{0.1}\right)$ and $10 \mathrm{mM}\left(\mathrm{GS}_{10}\right)$ glucose 6-phosphate. GS fractional velocity $\left(\mathrm{GS}_{\mathrm{Fv}}\right)$ was calculated as the ratio $\mathrm{GS}_{0.1} / \mathrm{GS}_{10}$.

Because basal study conditions were identical on the two separate days of study, biopsies were taken only at the end of the $15 \mathrm{mU} / \mathrm{m}^{2}$ per min insulin infusion on each occasion, with or without experimental FFA replacement. This allowed each subject to undergo only two, rather than four, muscle biopsies. PDH and GS activities were compared between these biopsies, assuming that under identical conditions, basal enzyme activities would be similar. 
Muscle fiber typing. Portions of the muscle biopsies were frozen in isopentane cooled to $-160^{\circ} \mathrm{C}$. For histochemical analysis, $10-\mu \mathrm{m}$ muscle sections were cut with a microtome from the frozen specimen and stained for myofibrillar adenosine triphosphatase $(23,24)$. The average cross-sectional area of 20 randomly selected fibers of each type (I, IIA, and IIB) was determined to assess the proportion of each fiber type.

\section{Calculations}

Leg balance for all substrates was calculated as the product of the arterio-venous concentration difference and leg blood flow (leg plasma flow for FFA balance). Leg plasma flow was estimated from measured leg blood flow by the equation: plasma flow $=($ blood flow $) \times(1-$ hematocrit) (16). Leg carbohydrate and lipid oxidation rates were calculated using the equations of Frayn (25), using an empiric value for limb protein oxidation, as previously described $(16,26)$. Fractional extraction of FFA by the leg was calculated as arteriovenous difference of $\left[{ }^{3} \mathrm{H}\right]$ palmitate dpm divided by the arterial palmitate dpm. Leg FFA uptake was calculated as ( fractional extraction $) \times($ arterial FFA $) \times($ leg plasma flow). Leg FFA release was calculated as the difference between leg FFA uptake and leg FFA net balance. Calculations of limb FFA uptake and release assume that the majority of plasma FFA species behave similarly to palmitate. Leg glucose storage was calculated as the difference between glucose uptake and the sum of glucose oxidation and net release of lactate and alanine, in glucose equivalents (16). The net release of lactate and alanine was taken to be an estimate of nonoxidized glycolysis. The total rate of glycolysis within leg tissue was estimated as the sum of glucose oxidation and net release of lactate and alanine.

\section{Statistics}

Data are expressed as mean \pm SEM. Statistical comparisons were made using repeated measures analysis of variance and paired $t$ tests where appropriate.

\section{Results}

Glucose clamp and experimental FFA replacement data. Basal concentrations ( times $t=-30$ to $0 \mathrm{~min}$ ) of arterial blood glucose, plasma insulin, and plasma FFA were nearly identical on each occasion, as shown in Fig. 1 and 2. During both studies, plasma insulin was acutely increased at $t=0$ to equivalent steady-state levels of moderate, physiologic hyperinsulinemia ( $\sim 200 \mathrm{pM}$ or $35 \mu \mathrm{U} / \mathrm{ml}$ ). Arterial blood glucose was maintained at euglycemia during each study. After starting insulin infusion alone, plasma FFA concentrations were rapidly and nearly completely suppressed; during insulin infusion and experimental FFA replacement, plasma FFA levels remained at basal concentrations as shown in Fig. 2.

Leg glucose uptake. Rates of leg glucose uptake during basal sampling periods were similar during each study (Fig. 3 ). Leg blood flow increased significantly from basal values to equivalent values with insulin infusion, regardless of whether FFA levels decreased or were experimentally maintained (from $2.4 \pm 0.2$ to $3.4 \pm 0.3$ compared to from $2.5 \pm 0.2$ to $3.6 \pm 0.3 \mathrm{ml} /$ min per $100 \mathrm{ml}$ leg tissue). Insulin-stimulated rates of leg glucose uptake were greater when plasma FFA concentrations were allowed to decrease than when they were maintained (Fig. 3 ). The decrease in steady-state rates of leg glucose uptake ( times $t=210$ to $240 \mathrm{~min}$ ) during maintenance of basal levels of FFA, as compared to insulin infusion alone, was $35 \pm 7 \%$. The rate of glucose infusion needed to maintain euglycemia during hyperinsulinemia was correspondingly greater when plasma FFA concentrations were allowed to decrease than
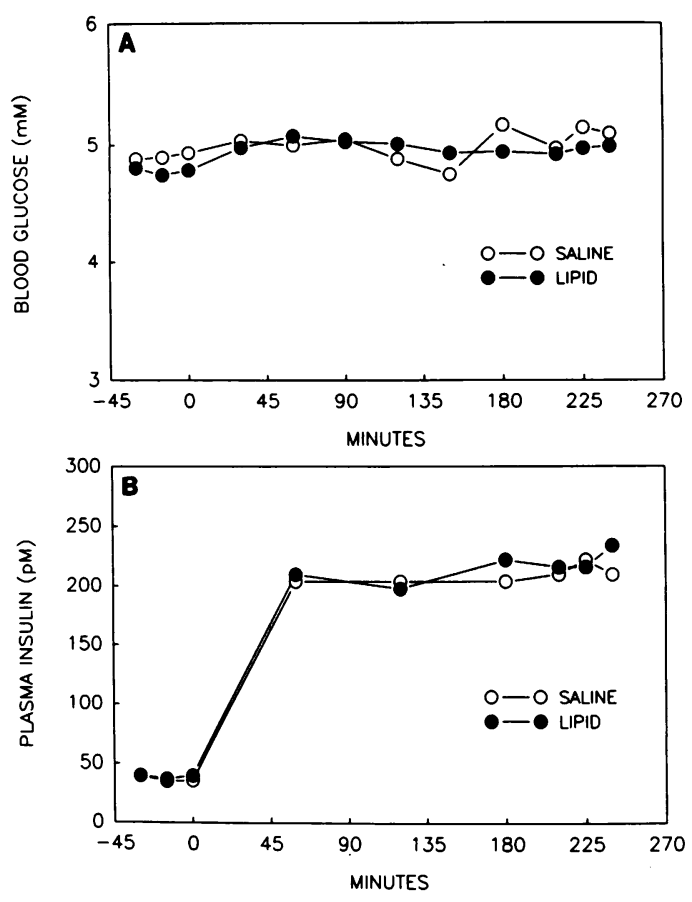

Figure 1. (A) Average blood glucose concentrations in 10 volunteers each studied on two separate occasions. On one occasion, plasma FFA were prevented from decreasing during the insulin infusion by infusion of $10 \%$ fat emulsion (closed circles). On the other occasion, plasma FFA were allowed to decrease during infusion of insulin and saline (open circles). ( $B$ ) Average plasma insulin concentrations in the 10 volunteers basally $(-30-0 \mathrm{~min})$ and during an infusion of insulin at a rate of $15 \mathrm{mU} / \mathrm{m}^{2}$ per min begun at time 0 .

when they were maintained at basal values, as shown in Fig. 3. The decrease in leg glucose uptake was significantly correlated with the decrease in the glucose infusion rate $(r=0.63, P$ $<0.05$ ).

Leg FFA uptake and release. During the basal periods on each occasion, fractional extraction of FFA across the leg, leg FFA uptake, and FFA release, were not significantly different, as shown in Table I. Fractional extraction of plasma FFA in-

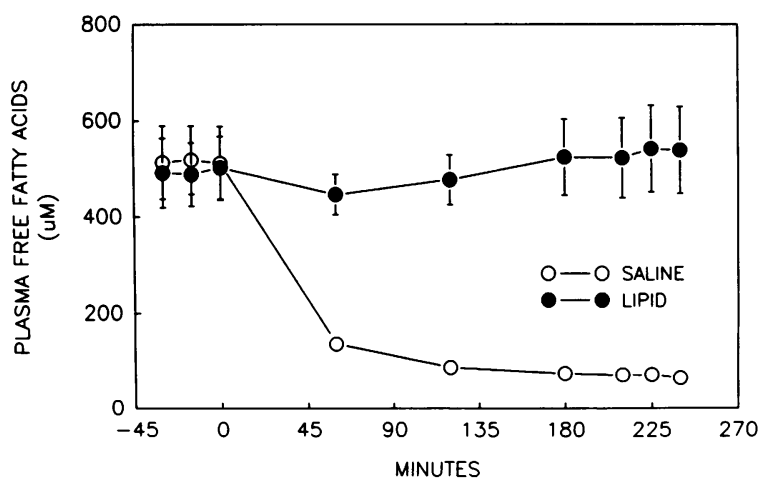

Figure 2. Plasma FFA concentrations in the 10 volunteers basally $(-30-0 \mathrm{~min})$ and during insulin infusion $(0-240 \mathrm{~min})$. On one occasion, FFA concentrations were prevented from decreasing during insulin infusion by simultaneous infusion of $10 \%$ fat emulsion (closed circles), and on the other occasion, plasma FFA concentrations were allowed to decrease (open circles). 

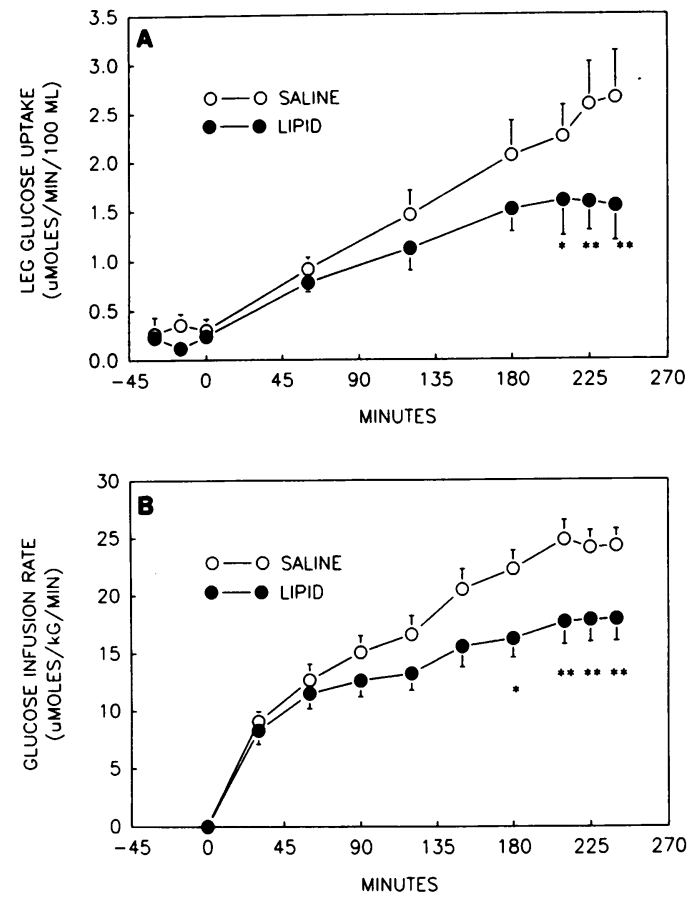

Figure 3. Time course of leg glucose uptake $(A)$ and the rate of glucose infusion required to maintain euglycemia $(B)$ in 10 volunteers studied with (closed circles) and without (open circles) FFA replacement during insulin infusion (0-240 $\mathrm{min}$ ).

creased to a similar extent during insulin infusion compared to basal values, whether or not plasma FFA concentrations were maintained. During insulin infusion alone, leg FFA uptake and release decreased compared to basal rates, and net leg FFA balance was not different from 0 (Table I). During insulin infusion when plasma FFA were maintained, leg FFA uptake doubled compared to basal rates, while leg FFA release did not change, and net balance of FFA across the leg became positive at a rate of $0.11 \pm 0.04 \mu \mathrm{mol} / \mathrm{min}$ per $100 \mathrm{ml} \mathrm{leg}$ tissue.

Leg glucose and lipid oxidation. Basal rates of oxidation of glucose and lipid by the leg were similar before insulin infusion in each study. During the basal periods on each occasion, the percentage of leg oxygen consumption accounted for by lipid oxidation $(\sim 60-70 \%)$ was greater than that accounted for by glucose oxidation (about 30-40\%). During infusion of insulin when plasma FFA levels were allowed to decrease, leg glucose oxidation and energy expenditure increased and leg lipid oxidation decreased significantly. During insulin infusion when plasma FFA concentrations were maintained, leg glucose oxidation increased significantly compared to basal rates and achieved a rate that was lower (though not statistically significantly) than during insulin infusion when plasma FFA concentrations fell. Moreover, leg lipid oxidation did not decrease from basal rates during insulin infusion when plasma FFA concentrations were experimentally maintained (Table II) and was significantly higher than the rate of leg lipid oxidation during insulin infusion alone. Leg energy expenditure increased significantly during insulin infusion whether or not FFA concentrations were maintained (Table II).

The pattern of leg oxygen consumption during insulin infusion was significantly altered when plasma FFA concentrations were experimentally maintained at basal values (Fig. 4 and Table II). During the insulin infusion when plasma FFA levels were allowed to decrease, glucose and lipid accounted for $76 \pm 8$ and $24 \pm 8 \%$, respectively, of leg oxygen consumption. However, when plasma FFA was maintained during insulin infusion, glucose and lipid accounted for $53 \pm 6$ and $47 \pm 6 \%$ of leg oxygen consumption (both $P<0.05$ ).

Leg glycolysis and glucose storage. Basal rates of leg net balance for lactate and alanine, which were negative and indicative of net release, were similar under basal conditions on each occasion (Table III). During infusion of insulin when plasma FFA concentrations decreased, net release of lactate and alanine did not change compared to basal rates. However, during infusion of insulin when plasma FFA concentrations were maintained, net leg release of lactate increased compared to basal rates, but net release of alanine did not change (Table III).

The sum of net leg balance of lactate and alanine (nonoxidized glycolysis) and leg glucose oxidation can be used as an estimate of leg total glycolytic flux. During insulin infusion when plasma FFA concentrations fell, the total rate of leg glycolysis was increased compared to basal conditions ( Table III), and this increment primarily was caused by an increase in leg glucose oxidation. During insulin infusion and experimental FFA replacement, the rate of leg glycolysis was also greater than during basal conditions, and furthermore, it was equivalent to that found during infusion of insulin alone. However, the equivalent overall rate of glycolysis during infusion of insulin when FFA concentrations were maintained was partly caused by increased net balance of lactate (Table III), with a lesser contribution of increased glucose oxidation than when plasma FFA levels fell.

Basal rates of net leg glucose storage were negative and equivalent during the two studies (Table III), indicative of net

Table I. Leg FFA Uptake and Release

\begin{tabular}{lrrrrr}
\hline & \multicolumn{2}{c}{ Basal } & & \multicolumn{2}{c}{ Insulin infusion } \\
\cline { 2 - 3 } & \multicolumn{1}{c}{ Saline } & FFA replacement study* & & Saline & FFA replacement \\
\hline Leg FFA fractional extraction & $0.39 \pm 0.03$ & $0.36 \pm 0.03$ & & $0.52 \pm 0.09^{\ddagger}$ & $0.47 \pm 0.05^{\ddagger}$ \\
Leg FFA uptake $(\mu \mathrm{mol} / \mathrm{min}$ per $100 \mathrm{ml})$ & $0.39 \pm 0.05$ & $0.28 \pm 0.03$ & & $0.11 \pm 0.02^{\S}$ & $0.54 \pm 0.10^{\ddagger \prime \prime}$ \\
Leg FFA net balance & $-0.20 \pm 0.06$ & $-0.13 \pm 0.04$ & & $0.01 \pm 0.01^{\S}$ & $0.11 \pm 0.04^{\S \|}$ \\
Leg FFA release & $0.59 \pm 0.08$ & $0.41 \pm 0.06$ & & $0.10 \pm 0.02^{\S}$ & $0.42 \pm 0.09^{\| \prime}$ \\
& & & &
\end{tabular}

Data are expressed as mean \pm SEM. * Basal conditions were identical on both occasions before insulin infusions with or without infusion of $10 \%$ fat emulsion. Basal vs insulin, ${ }^{\ddagger} P<0.05,{ }^{\S} P<0.01$. Saline vs FFA replacement, $" P<0.01$. 


\begin{tabular}{lcccc}
\hline & \multicolumn{2}{c}{ Basal } & \multicolumn{2}{c}{ Insulin infusion } \\
\cline { 2 - 5 } & Saline & FFA replacement study* & Saline & FFA replacement \\
\hline Leg glucose oxidation & $0.40 \pm 0.09$ & $0.28 \pm 0.07$ & $0.99 \pm 0.16^{\ddagger}$ & $0.81 \pm 0.15^{\ddagger}$ \\
Leg lipid oxidation & $0.15 \pm 0.02$ & $0.22 \pm 0.04$ & $0.08 \pm 0.01^{\ddagger}$ & $0.17 \pm 0.03^{5}$ \\
Leg energy expenditure & $0.66 \pm 0.07$ & $0.75 \pm 0.10$ & $0.88 \pm 0.11^{\ddagger}$ & $0.98 \pm 0.15^{\ddagger}$ \\
Leg $R_{\mathrm{q}}$ & $0.82 \pm 0.02$ & $0.78 \pm 0.02$ & $0.93 \pm 0.02^{\ddagger}$ & $0.86 \pm 0.02^{\ddagger 5}$ \\
Oxygen consumption & & & & \\
$\quad$ Percent glucose & $38 \pm 7$ & $26 \pm 7$ & $76 \pm 8^{\ddagger}$ & $53 \pm 6^{\ddagger \S}$ \\
Percent lipid & $62 \pm 7$ & $74 \pm 7$ & $24 \pm 8$ & $47 \pm 6^{\ddagger 5}$ \\
\hline
\end{tabular}

Data are expressed as mean \pm SEM. Units are $\mu \mathrm{mol} / \mathrm{min}$ per $100 \mathrm{ml}$ leg tissue. ${ }^{*}$ Basal conditions were identical on the two occasions before insulin infusion with or without lipid replacement. ${ }^{\ddagger} P<0.05$ basal vs insulin. ${ }^{\S} P<0.05$ saline vs FFA replacement.

glycogenolysis in resting skeletal muscle during postabsorptive conditions. During insulin infusion when plasma FFA concentrations decreased, leg glucose storage increased significantly (Table III), and accounted for $51 \pm 5 \%$ of leg glucose uptake. However, during insulin infusion and FFA replacement, leg glucose storage increased only modestly compared to basal rates, and was significantly lower than during insulin infusion (Table III), accounting for only $23 \%$ of leg glucose uptake. The contributions of leg glucose oxidation, storage, and nonoxidized glycolysis to leg glucose uptake during insulin infusion with or without FFA replacement are shown in Fig. 5.

Muscle $P D H$ and GS activity. $\mathrm{PDH}_{\mathrm{a}}$, the active form of $\mathrm{PDH}$, was significantly decreased in muscle biopsies taken during insulin infusion and FFA replacement, compared to when FFA concentrations were allowed to decrease (Table IV). This decrease averaged $\sim 50 \%$. $\mathrm{PDH}_{\mathrm{t}}$ activity was not significantly decreased during FFA replacement. $\mathrm{GS}_{\mathrm{Fv}}\left(\mathrm{GS}_{0.1} / \mathrm{GS}_{10}\right)$ was also significantly decreased when plasma FFA concentrations were maintained, indicating a suppressive effect of FFA on insulin action in muscle.

Muscle fiber type analysis. Myofibrillar ATPase staining of thin sections of muscle biopsies revealed that type IIa $(47 \pm 2 \%)$ and IIb $(20 \pm 2 \%)$ fast-twitch fibers were the most numerous, compared to type I slow-twitch $(34 \pm 3 \%)$. The cross-sectional areas accounted for by these fiber types were $6,010 \pm 572$,

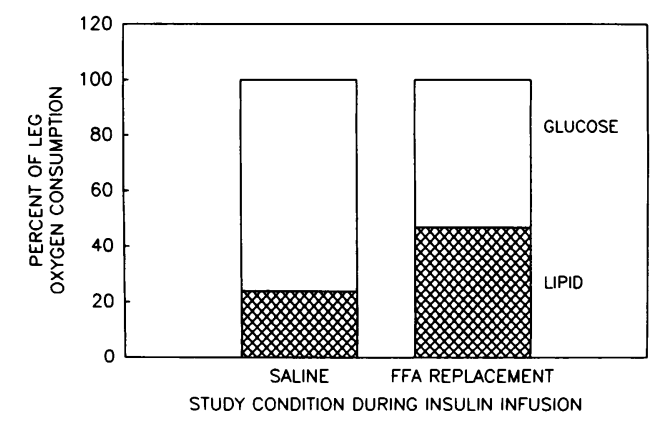

Figure 4. Percent of leg total oxygen consumption accounted for by glucose (open bar) and lipid (hatched bar) during a $15-\mathrm{mU} / \mathrm{m}^{2}$ per min insulin infusion with or without FFA replacement by $10 \%$ intralipid infusion. The percent of oxygen consumption caused by lipid was significantly $(P<0.05)$ greater during insulin infusion when plasma FFAs were replaced.
$5,086 \pm 321$, and $4,485 \pm 451 \mu \mathrm{m}^{2}$ for types I, IIa, and IIb, respectively.

\section{Discussion}

The present study was undertaken for two purposes: $(a)$ to determine how experimental maintenance of plasma FFA concentrations during physiologic hyperinsulinemia alters leg muscle glucose uptake, storage, oxidation, and glycolysis in normal healthy volunteers; and $(b)$ to determine whether changes in muscle PDH and GS activities accompany changes in glucose oxidation and glycogen synthesis, respectively. The classical glucose/fatty acid fuel competition hypothesis predicts that muscle glucose uptake, glycolysis, glucose oxidation, and PDH activity would be decreased by FFA oxidation.

The current results show that maintenance of plasma FFA levels by means of a triglyceride infusion during hyperinsulinemia suppresses leg muscle glucose uptake by $25 \%$ and PDH activity by nearly $50 \%$. This is, to our knowledge, the first demonstration of the effect of FFA oxidation on PDH activity in human skeletal muscle. Paradoxically, this decrease in PDH activity and glucose uptake was not accompanied by a significant decrease in the rate of leg muscle glucose oxidation. However, leg muscle respiratory quotient $\left(R_{Q}\right)$ was significantly decreased during FFA maintenance, and in fact leg lipid oxidation was significantly increased. In this study, we chose a modest, physiologic level of hyperinsulinemia that would not completely suppress lipid oxidation. It could be calculated that during hyperinsulinemia alone, glucose oxidation accounted for $76 \%$ of leg oxygen consumption, but that during hyperinsulinemia and FFA replacement, glucose oxidation was decreased significantly to only $53 \%$ of leg oxygen consumption. Because total leg muscle energy expenditure was not significantly greater during FFA replacement, these findings are consistent with both a shift away from glucose as an oxidative substrate and decreased muscle PDH activity.

Our results and those of other investigators who have assessed the effect of FFA on glucose oxidation would suggest that although FFA oxidation suppresses glucose oxidation in human muscle, this is a subtle effect $(8,10,13,14)$. On the other hand, observations in rat diaphragm and cardiac muscle have shown that FFA strongly inhibits glucose oxidation (3, 4 ). The differences between the results of human and rat stud- 
Table III. Leg Glucose Uptake, Oxidation, Nonoxidized Glycolysis, and Glucose Storage

\begin{tabular}{|c|c|c|c|c|}
\hline & \multicolumn{2}{|c|}{ Basal } & \multicolumn{2}{|c|}{ Insulin infusion } \\
\hline & Saline & FFA replacement study* & Saline & FFA replacement \\
\hline Leg glucose uptake & $0.24 \pm 0.07$ & $0.19 \pm 0.04$ & $2.44 \pm 0.39^{\prime \prime}$ & $1.57 \pm 0.31^{11 * *}$ \\
\hline Glycolysis & $0.57 \pm 0.12$ & $0.43 \pm 0.10$ & $1.20 \pm 0.21^{11}$ & $1.22 \pm 0.18^{\prime \prime}$ \\
\hline Glucose oxidation & $0.40 \pm 0.09$ & $0.28 \pm 0.07$ & $0.99 \pm 0.16^{11}$ & $0.81 \pm 0.15^{\prime \prime}$ \\
\hline$(\%)$ & $(65 \pm 9)$ & $(61 \pm 9)$ & $(84 \pm 4)^{\| \prime}$ & $(64 \pm 5)^{* *}$ \\
\hline Nonoxidized $^{\circ}$ & $-0.17 \pm 0.05$ & $-0.16 \pm 0.03$ & $-0.21 \pm 0.08$ & $-0.41 \pm 0.06^{81}$ \\
\hline$(\%)$ & $(35 \pm 9)$ & $(39 \pm 9)$ & $(16 \pm 4)^{\ddagger}$ & $(36 \pm 5)^{* *}$ \\
\hline Lactate balance & $-0.16 \pm 0.08$ & $-0.18 \pm 0.08$ & $-0.20 \pm 0.14$ & $-0.70 \pm 0.14^{11 * *}$ \\
\hline Alanine balance & $-0.18 \pm 0.04$ & $-0.11 \pm 0.02$ & $-0.23 \pm 0.04$ & $-0.13 \pm 0.03$ \\
\hline Glucose storage & $-0.33 \pm 0.11$ & $-0.23 \pm 0.08$ & $1.24 \pm 0.25^{\prime \prime}$ & $0.36 \pm 0.20^{\S * *}$ \\
\hline
\end{tabular}

Data are given as mean \pm SEM. Units are $\mu \mathrm{mol} / \mathrm{min}$ per $100 \mathrm{ml} \mathrm{leg} \mathrm{tissue.}{ }^{*}$ Basal conditions were identical on both occasions. ${ }^{\ddagger}$ Nonoxidized glycolysis = sum of lactate and alanine balance expressed as glucose equivalents. Negative net balance indicates net release and is considered as a positive contribution to glucose metabolism. Basal vs insulin ${ }^{8} P<0.05$, " $P<0.01$; saline vs FFA replacement ${ }^{1} P<0.05$, ${ }^{* *} P<0.01$.

ies may be a species effect, or may be caused in part by different muscle fiber type composition. Diaphragm and cardiac muscle, which have been studied in the rat are made up of chronically contracting, slow-twitch fibers with a high capacity for lipid oxidation, while human leg muscle is a more mixed muscle composed of about two-thirds type II and one-third type I fibers.

The classical formulation of the fuel competition hypothesis also predicts that glycolysis would be decreased by maintaining FFA oxidation during hyperinsulinemia. The present findings do not support the existence of this phenomenon in human muscle, since total leg muscle glycolysis during hyperinsulinemia was unchanged by FFA replacement. Consistent with earlier studies, during hyperinsulinemia alone, leg net lactate balance increased little $(16,27)$. However, during FFA replacement leg lactate release was significantly increased, suggesting that nonoxidized glycolytic flux may have been increased rather than decreased as predicted. An increase in glycolysis to pyruvate/lactate may also have at least partially counterbalanced the decrease in PDH activity by providing more substrate, accounting for the inability to observe decreased rates of leg glucose oxidation.

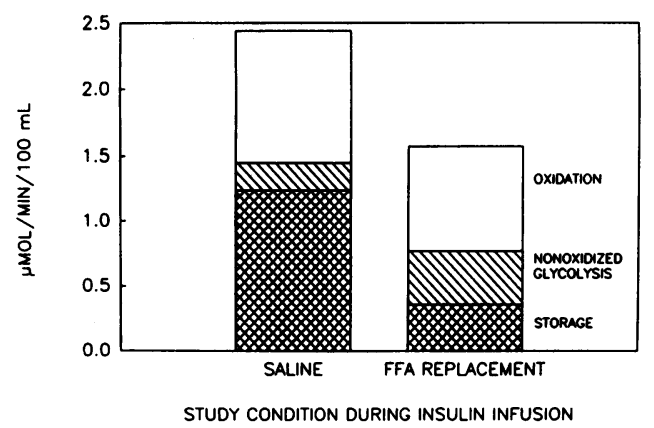

Figure 5. Contributions of leg glucose oxidation (open bar) nonoxidized glycolysis ( hatched bar), and glucose storage (crosshatched bar) to leg glucose uptake during a $15-\mathrm{mU} / \mathrm{m}^{2}$ per min insulin infusion with or without FFA replacement. Leg glucose storage was signifcantly $(P<0.01)$ decreased during FFA replacement and accounted for most of the deficit in leg glucose uptake.
The greatest effect of maintenance of leg FFA uptake and oxidation during hyperinsulinemia was to decrease leg glucose storage as glycogen by $\sim 70 \%$. This deficit was of nearly the same magnitude as the decrease in leg muscle glucose uptake, and the decrease in glucose storage was significantly correlated with the decrease in glucose uptake. The decrease in leg muscle glucose uptake also was closely paralleled by a suppression of the rate of infusion of glucose required to maintain euglycemia during the insulin infusion. Accompanying the decrease in leg glucose storage was a $25 \%$ decrease in muscle GS fractional velocity, which is a sensitive indicator of the ability of insulin to stimulate glycogen synthesis $(17,28)$. Not all investigators have found that FFA replacement during physiologic hyperinsulinemia inhibits insulin stimulation of systemic glucose storage (13). However, the present findings are similar to the decrease in muscle glycogen synthase activity and systemic glucose storage observed previously using a greater rate of lipid infusion than we employed (14). The failure to observe decreased glucose storage in some studies may be explained by different time courses of the effects of FFA on glucose oxidation and storage. Boden et al. (14) found that FFA maintenance during hyperinsulinemia first suppresses glucose oxidation and only later, after $\sim 4 \mathrm{~h}$, decreases glucose storage. Studies that were not carried out for a long enough time may result in only the effect of FFA on glucose oxidation being observed.

The ability of FFA to suppress glucose storage and glycogen synthase activity we and others (14) have found is similar to the in vitro findings of Argyraki et al. (29), who used human skeletal muscle strips incubated in vitro. Those studies showed that increasing FFA concentrations suppressed insulin-stimulated glycogen synthesis in a dose-responsive manner, but glycogen synthase activity was not measured in those studies. Other in vitro evidence (30) suggests that palmitoyl-CoA inhibits GS activity, providing a potential mechanism for inhibition of GS by FFA oxidation. Although it is likely that suppression of glycogen synthesis by fat oxidation was caused by decreased glycogen synthase activity, it also has been shown that high fat feeding in rats also inhibits glucose transport in skeletal muscle (31), suggesting that fatty acids also may exert an effect on the activity or number of skeletal muscle glucose transporters. Boden et al. (14) hypothesized that the effect of FFA on 
Table IV. Effect of FFA Replacement on Muscle Enzyme Activities

\begin{tabular}{lccccrr}
\hline & $\mathrm{PDH}_{\mathrm{a}}$ & $\mathrm{PDH}_{\mathrm{i}}$ & $\mathrm{PDH}_{\mathrm{Fv}}$ & $\mathrm{GS}_{0.1}$ & $\mathrm{GS}_{\mathrm{10}}$ & $\mathrm{GS}_{\mathrm{Fv}}$ \\
\hline Saline & $0.639 \pm 0.132$ & $1.01 \pm 0.22$ & $0.81 \pm 0.22$ & $0.719 \pm 0.258$ & $4.65 \pm 1.48$ & $0.169 \pm 0.033$ \\
FFA replacement & $0.328 \pm 0.053^{*}$ & $0.662 \pm 0.176$ & $0.67 \pm 0.10$ & $0.567 \pm 0.183$ & $4.39 \pm 1.25$ & $0.129 \pm 0.026^{\ddagger}$ \\
\hline
\end{tabular}

${ }^{*} P<0.05,{ }^{\ddagger} P<0.01$ saline vs FFA replacement. Enzyme activities are expressed as mean \pm SEM, in units of nanomoles substrate converted per minute per milligram extract protein. See Methods for details.

glucose storage and GS activity might be secondary to an alteration of the glucose transport system in muscle. This could either be a direct effect of alterations in composition of the lipid bilayer environment of the plasma membrane glucose transporter or a feedback inhibition of glycolytic intermediates. Moreover, it has also been suggested that the mild elevation in triglycerides seen during intralipid infusion might alter glucose transport (32).

Our results also document that maintenance of plasma FFA concentrations by a lipid infusion during hyperinsulinemia in fact maintains leg muscle FFA uptake and oxidation. This was made possible by the use of a tritiated palmitate tracer to assess palmitate extraction, since FFA is simultaneously taken up and released by muscle. The assumption inherent in this technique is that palmitate behaves similarly to other fatty acids in plasma, such as oleic and linoleic acid. Our results also would suggest that fractional extraction of FFA increases during hyperinsulinemia, whether or not plasma FFA is maintained. This may have been a manifestation of an increase in leg blood flow during hyperinsulinemia, which has been documented elsewhere (33). It is also possible that inhibition of intramuscular lipolysis and enhancement of reesterification by insulin resulted in increased FFA uptake independently of changes in blood flow. It should be noted that hydrolysis of infused triglyceride within the leg may have somewhat affected measurement of $\left[{ }^{3} \mathrm{H}\right]$ palmitate uptake by changing the palmitate-specific activity within the leg circulation. However, the insulin infusion would work to decrease lipolysis, so this effect may not have been pronounced. Regardless, maintenance of fat oxidation by lipid infusion was confirmed by the independent technique of leg indirect calorimetry.

Finally, the current results may have important implications regarding the mechanisms of insulin resistance in NIDDM. A number of studies have shown that during hyperinsulinemia, patients with NIDDM have a more pronounced defect in glucose storage and GS activity than in glucose oxidation, along with a failure to suppress leg lipid oxidation (34). The fact that this pattern is similar to that produced in nondiabetic volunteers by maintaining fat oxidation during an insulin infusion suggests that defects in suppression of lipolysis or maintenance of fat oxidation may be involved in the pathogenesis of skeletal muscle insulin resistance in NIDDM.

\section{Acknowledgments}

The expert technical assistance of J. Finlayson, D. Bookey, and B. Jefferson and the excellent editorial assistance of J. Smith and G. Gutkowski is gratefully acknowledged.

This work was supported by funds from the American Diabetes Association, The Medical Research Service, Department of Veterans'
Affairs, and The National Institutes of Health (R01 DK41075, M01 RR 0056).

\section{References}

1. Randle, P. J., P. B. Garland, C. N. Hales, and E. A. Newsholme. 1963. The glucose fatty-acid cycle. Its role in insulin sensitivity and the metabolic disturbances of diabetes mellitus. Lancet. i:785-789.

2. Randle, P. J., E. A. Newsholme, and P. B. Garland. 1964. Regulation of glucose uptake by muscle. Biochem. J. 93:652-665.

3. Randle, P. J. 1986. Fuel selection in animals. Biochem. Soc. Trans. 14:799806.

4. Randle, P. J., A. Kerbey, and J. Espinal. 1988. Mechanisms decreasing glucose oxidation in diabetes and starvation: Role of lipid fuels and hormones. Diabetes Metab. Rev. 4:623-638.

5. Felber, J.-P., E. Ferrannini, A. Golay, H. Meyer, D. Thiebaud, B. Curchod, E. Maeder, E. Jequier, and R. DeFronzo. 1987. Role of lipid oxidation in pathogenesis of insulin resistance of obesity and type II diabetes. Diabetes. 36:13411350 .

6. Vaag, A., P. Skött, P. Damsbo, M.-A. Gall, E. A. Richter, and H. Beck-Nielsen. 1991. Effect of the antilipolytic nicotinic acid analog acipimox on wholebody and skeletal muscle glucose metabolism in patients with non-insulin-dependent diabetes mellitus. J. Clin. Invest. 88:1282-1290.

7. Bevilacqua, S., G. Buzziagoli, R. Bonadonna, L. Brandi, M. Oleggini, C. Boni, M. Geloni, and E. Ferrannini. 1990. Operation of Randle's cycle in patients with NIDDM. Diabetes. 39:383-389.

8. Thiebaud, D., R. A. DeFronzo, E. Jacot, A. Colay, K. Acheson, E. Maeder, E. Jequier, and J.-P. Felber. 1982. Effect of long chain triglyceride infusion on glucose metabolism in man. Metabolism. 31:1128-1136.

9. Ferrannini, E., E. J. Barrett, S. Bevilacqua, and R. A. DeFronzo. 1983. Effect of fatty acids on glucose production and utilization in man. J. Clin. Invest. 72:1737-1747.

10. Wolfe, B. M., S. Klein, E. J. Peters, B. F. Schmidt, and R. R. Wolfe. 1988. Effect of elevated free fatty acids on glucose oxidation in normal humans. Metabolism. 37:323-329.

11. Walker, M., G. R. Fulcher, C. Catalana, G. Petranyi, H. Orskov, and K. G. M. M. Alberti. 1990. Physiological levels of plasma non-esterified fatty acids impair forearm glucose uptake in normal man. Clin. Sci. 79:167-174.

12. Walker, M., G. R. Fulcher, C. F. Sum, H. Orskov, and K. G. M. M. Alberti. 1991. Effect of glycemia and nonesterified fatty acids on forearm glucose uptake in normal humans. Am. J. Physiol. 261 (Endocrinol. Metab. 24):E304E311.

13. Groop, L. C., R. C. Bonadonna, M. Shank, A. S. Petrides, and R. A. DeFronzo. 1991. Role of free fatty acids and insulin in determining free fatty acid and lipid oxidation in man. J. Clin. Invest. 87:83-89.

14. Boden, G., F. Jadali, J. White, Y. Liang, M. Mozzoli, X. Chen, E. Coleman, and C. Smith. 1991. Effects of fat on insulin-stimulated carbohydrate metabolism in normal men. J. Clin. Invest. 88:960-966.

15. Johnson, A. B., M. Argyraki, J. C. Thow, B. G. Cooper, G. Fulcher, and R. Taylor. 1992. Effect of increased free fatty acid supply on glucose metabolism and skeletal muscle glycogen synthase activity in normal man. Clin. Sci. 82:219-226.

16. Kelley, D., J. Reilly, T. Veneman, and L. Mandarino. 1990. The influence of physiologic hyperinsulinemia on skeletal muscle glucose storage oxidation, and glycolysis in man. Am. J. Physiol. 258:E923-E929.

17. Mandarino, L., K. Wright, L. Verity, J. Nichols, J. Bell, O. Kolterman, and H. Beck-Nielsen. 1987. Effects of insulin infusion on human skeletal muscle pyruvate dehydrogenase, phosphofructokinase and glycogen synthase. J. Clin. Invest. 80:655-663.

18. Passoneau, J. 1972. Lactate. In Methods of Enzymatic Analysis. H. Bergmeyer, editor. Academic Press, Inc., New York, 1468-1472.

19. Karl, I., A. Pagliara, and D. Kipnis. 1972. A microfluorometric enzymatic assay for determination of alanine and pyruvate in plasma and tissue. J. Lab. Clin. Med. 80:434-441. 
20. Douglas, A., N. Jones, and J. Reed. 1988. Calculation of whole blood $\mathrm{CO}_{2}$ content. J. Appl. Physiol. 65:473-477.

21. Herbert, V., L. Lau, C. Gottleib, and S. Bleicher. 1965. Coated charcoal immunoassay of insulin. J. Clin. Endocrinol. \& Metab. 25:1375-1384.

22. Miles, J., M. Ellman, K. McClean, and M. Jensen. 1987. Validation of a new method for determination of free fatty acid turnover. Am. J. Physiol. 252:E431-E438.

23. Simoneau, J.-A., G. Lortie, M. R. Boulay, M.-C. Thibault, and C. Bouchard. 1986. Repeatability of fibre type and enzyme activity measurements in human skeletal muscle. Clin. Physiol. 6:347-356.

24. Simoneau, J.-A., and C. Bouchard. 1989. Human variation in skeletal muscle fiber-type proportion and enzyme activities. Am. J. Physiol. 257 (Endocrinol. Metab. 29):E567-E572.

25. Frayn, K. 1983. Calculation of substrate oxidation rates in vivo from gaseous exchange. J. Appl. Physiol. 55:628-634.

26. Gelfand, R. A., and E. J. Barrett. 1987. Effect of physiologic hyperinsulinemia on skeletal muscle protein synthesis and breakdown in man. J. Clin. Invest. 80:1-6.

27. Consoli, A., N. Nurjahan, J. Gerich, and L. Mandarino. 1992. Skeletal muscle in a major site of lactate uptake and release during hyperinsulinemia. Metabolism. 41:176-179.
28. Bogardus, C., S. Lillioja, K. Stone, and D. Mott. 1984. Correlation between muscle glycogen synthase activity and in vivo insulin action in man. $J$. Clin. Invest. 73:1185-1190.

29. Argyraki, M., P. D. Wright, C. W. Venables, G. Proud, and R. Taylor. 1989. In vitro study of human skeletal muscle strips: effect of nonesterified fatty acid supply on glucose storage. Metabolism. 38:1183-1187.

30. Wititsuwannakul, D., and K. H. Kim. 1977. Mechanism of palmitoyl coenzyme A inhibition of liver glycogen synthase. J. Biol. Chem. 252:7812-7817.

31. Grundleger, M., and S. Thenen. 1982. Decreased insulin binding, glucose transport, and glucose metabolism in soleus muscle of rats fed a high fat diet. Diabetes. 31:232-237.

32. Hargreaves, M., B. Kiens, E. Richter. 1991. Effect of increased plasma free fatty acid concentrations on muscle metabolism in exercising men. J. Appl. Physiol. 70:194-201.

33. Laakso, M., S. Edelman, G. Brechtel, and A. Baron. 1987. Decreased effect of insulin to simulate skeletal muscle blood flow in obese man. J. Clin. Invest. 85:1844-1852.

34. Kelley, D., M. Mokan, and L. Mandarino. 1992. Intracellular defects in glucose metabolism in obese patients with NIDDM. Diabetes. 41:698-706. 